\title{
Senhoras e escravos na São Paulo do café (1840-1870)*
}

\author{
Eni de Mesquita Samara (USP) et. alii \\ André Félix Marques da Silva (USP) \\ Breno Henrique Selmine Matrangolo (USP) \\ Nadia Beyeler (USP) \\ Patrícia Garcia Ernando da Silva (USP)
}

\begin{abstract}
Resumo. Este artigo tem por objetivo estudar as mulheres proprietárias de bens e escravos na cidade de São Paulo no período de 1840-1870, utilizando como fonte documental os testamentos do $3^{\circ}$ Ofício da Família, pertencentes ao ATJSP (Arquivo do Tribunal de Justiça do Estado de São Paulo) e também ao acervo do CEDHAL (Centro de Demografia Histórica da América Latina). A proposta é analisar o processo de circulação de riqueza na cidade, buscando entender, principalmente, a constituição das fortunas femininas e a distribuição dos legados entre os herdeiros. Nesse sentido, será dada atenção especial às proprietárias com escravarias, de modo a compreender as condições em que as alforrias eram concedidas e qual era o papel desempenhado pelos cativos na transmissão dos patrimônios.

Palavras-chave: Mulheres. Patrimônio. São Paulo. Brasil Império. Família. Gênero.

Na primeira metade do século XIX, São Paulo começa a passar por transformações sociais e econômicas, que vão aos poucos modificando o perfil da cidade. Com o desenvolvimento propiciado pela cana-de-açúcar e o início do período cafeeiro, os contornos urbanos vão se tornando mais nítidos e começa a ocorrer um visível aumento do número de habitantes.
\end{abstract}

${ }^{*}$ Pesquisa financiada pelo CNPq.

Anos 90, Porto Alegre, v. 14, n. 25, p.37-64, jul. 2007 
Senhoras e escravos na São Paulo do café (1840-1870)

A cidade, que possuía 21.933 habitantes em 1836, em 1872, considerando apenas suas freguesias urbanas, a saber Sé, Santa Ifigênia, Consolação e Brás, já contava com 31.385 indivíduos. Essa população, por sua vez, estava distribuída por uma grande diversidade de espaços e atividades econômicas, que compunham um cenário de transição entre uma cidade com características coloniais e aquela que viria a ser um dos maiores centros urbanos do país no início do século XX. ${ }^{1}$

$\mathrm{E}$ é nesse contexto que pretendemos analisar a atuação das mulheres das várias categorias sociais e, em especial, aquelas donas de bens e de escravos, de modo a entender o processo de acumulação e circulação da riqueza nesse período e a constituição das fortunas femininas.

Sabemos que o processo de urbanização da cidade propiciou concomitantemente a concentração da riqueza e a proliferação da pobreza, e que, embora tenha crescido em um ritmo acelerado, esse evento não repercutiu em um acesso igualitário às oportunidades de enriquecimento, restando aos setores menos abastados da população atuar em ocupações desprestigiadas e de baixa remuneração.

Fato esse que pode ser apontado como um dos fatores que explicam a grande incidência de mulheres chefiando domicílios na cidade de São Paulo, já que elas estavam entre os setores que mais sofriam o peso da desigualdade econômica. Em 1836, por exemplo, encontramos uma população composta de 10.902 homens e 11.031 mulheres, quadro que reflete uma razão de masculinidade de 98,83 , ou seja, para cada 100 mulheres na cidade existiam 98 homens. Ainda pelo mesmo censo, dos 1.516 domicílios existentes, 542 eram chefiados por mulheres, totalizando $35,8 \%{ }^{2}$

Vem daí a importância de melhor contextualizarmos esses dados, analisando outros corpos documentais do período, como 
Eni de Mesquita Samara et. al.

por exemplo, os testamentos, de modo a conhecermos não só a constituição das suas famílias, patrimônios e formas de distribuição entre os herdeiros, mas também de informar as disposições de última vontade das mulheres que viviam na cidade e em seus arredores.

Estudiosos que analisaram a cidade de São Paulo na primeira metade dos oitocentos ${ }^{3}$ consideram que a riqueza estava distribuída entre três grandes grupos. No topo da pirâmide e, em pequeno número, ficavam os indivíduos que haviam acumulado riqueza mercantil e reinvestiam nos engenhos das novas áreas agrícolas. Suas viúvas e filhos mantiveram os mesmos padrões de investimento, reduziram o número de filhos e se casavam no mesmo grupo. Daí terem permanecido no topo da elite econômica.

Um segundo conjunto era composto por negociantes, agricultores e funcionários bem-sucedidos, e a sua riqueza era totalmente aplicada em negócios. Para Araújo (2006), essa era a categoria com maior capital de risco mercantil e que formava o mais importante mercado de bens de luxo da cidade.

Compunham, ainda, esse quadro, um terceiro grupo, também de negociantes, dedicado à venda a retalhos que movimentavam os negócios locais e tinham o perfil de consumidores das mercadorias urbanas. Fato que apresenta fortes indícios da constituição de camadas médias nessa sociedade, o que também foi apontado por Nazzari ${ }^{4}$ que, a partir da análise dos inventários, constata a existência de famílias urbanas possuidoras de poucos bens, mas com nível educacional e itens domésticos próprios da elite, cuja renda provinha de profissões liberais ou da carreira no exército.

Como se pode perceber, a cidade vive um momento de mudanças que podem ser notadas nos documentos dessa época, e tudo indica que, a partir de 1840, há um novo crescimento da riqueza, especialmente com a expansão da lavoura cafeeira.

Apesar de a maior parte dos autores concentrarem seus estudos no final do período colonial ou na virada do século XX, dada a 
Senhoras e escravos na São Paulo do café (1840-1870)

importância das transformações políticas e econômicas que aí ocorrem, pouco conhecemos da História de São Paulo entre os anos de 1840 e 1870. Entretanto, fatos importantes ocorrem nesse período, em especial, a Lei de Terras em 1850 e a abolição do tráfico no mesmo ano, e que repercutem diretamente na sociedade e economia da época.

Percebendo essa lacuna constituímos um Banco de Dados a partir dos testamentos manuscritos desse período, não só pela sua importância como fontes históricas, mas, sobretudo, pela diversidade dos personagens que nos relatam diferentes modos de vida nas várias camadas sociais, o que nos permite entender melhor os reflexos das mudanças que ocorrem com a vinda do café.

\section{Fontes documentais e Metodologia de trabalho}

Por registrarem destino do patrimônio, desde objetos de uso pessoal até escravos e grandes propriedades, além das últimas vontades de uma pessoa com relação a disposições religiosas, como missas e pedidos para o enterro, os testamentos foram escolhidos como fonte documental para o presente estudo sobre a transmissão de bens. ${ }^{5}$

Pertencentes originalmente ao Arquivo do Tribunal de Justiça do Estado de São Paulo, os testamentos do $3^{\circ}$ Ofício da Família foram microfilmados, fotocopiados e encontram-se arquivados atualmente no CEDHAL (Centro de Estudos de Demografia Histórica da América Latina). São ao todo 644 documentos entre os anos de 1763 e 1877: 621 testamentos e 23 codicilos. Desse total, 298 são de mulheres, 304 são de homens e 19 de mão comum. ${ }^{6}$ 


\section{Gráfico 1}

\section{Distribuição dos documentos do ATJSP/CEDHAL por gênero}
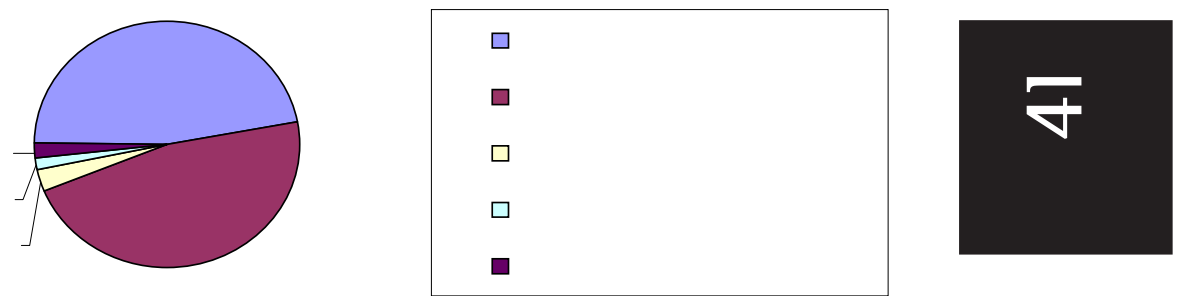

Fonte: Testamentos. $3^{\circ}$ Ofício da Família. São Paulo (Capital e Interior), 17631877. ATJSP/CEDHAL.

Para um melhor tratamento das fontes, elaboramos um Banco de Dados de Testamentos do $3^{\circ}$ Ofício da Família, em formato Access, no qual inserimos as informações através de tabelas e formulários. Na tabela Cadastro do Testador, inserimos os dados que, em geral, aparecem nos documentos: nome do testador, ocupação, irmandade a que pertence, religião, naturalidade, nacionalidade, estado de saúde, situação conjugal, autoria do testamento, descrições de imóveis, jóias, escravos, dívidas, utensílios, móveis e objetos.

$\mathrm{Na}$ tabela Filiação do Testador, colocamos as informações referentes aos pais das testadoras: nome, idade, nacionalidade, naturalidade, local de moradia e status jurídico, incluindo a questão da legitimidade e se os pais ainda eram vivos.

$\mathrm{Na}$ tabela Casamentos e Filhos, contemplamos os números de filhos vivos e mortos do testador e os dados sobre seu(s) cônjuge(s). $\mathrm{Na}$ tabela complementar Casamentos e Filhos, inserimos o nome dos filhos do testador, sua ocupação, seu estado conjugal, o nome de seu cônjuge, além de ratificações do recebimento da herança e informações adicionais.

Já na tabela Cadastro de Testamenteiros, registramos os seguintes dados: nome dos testamenteiros, relação com o testador, ordem

Anos 90, Porto Alegre, v. 14, n. 25, p.37-64, jul. 2007 
Senhoras e escravos na São Paulo do café (1840-1870)

de nomeação e observações adicionais sobre disposições a respeito daqueles que iriam cumprir as aspirações de última vontade.

As testadoras poderiam apresentar, ainda, as disposições após a morte, como local de enterro, amortalhamento, acompanhantes, número de missas, doações e esmolas, encomendação da alma e prazo para o cumprimento do testamento. Essas informações foram inseridas na tabela Cadastro de Disposições.

Para a análise da transmissão de bens utilizamos, especialmente, as informações referentes àqueles que recebiam a terça parte dos bens do testador, incorporando na tabela Cadastro de Legatários seus nomes e bens que receberam, tais como: imóveis, objetos, escravos e os respectivos valores, além das informações sobre quantias em dinheiro remanescente ou valor inteiro da terça.

Sistematizamos, ainda, duas tabelas com informações sobre os escravos, contendo nome, idade, nome e status jurídico dos pais. Fizemos também uma diferenciação entre os escravos que permaneceriam na condição de cativos, registrando-os na tabela Escravos, e aqueles que seriam libertos, inserindo-os na tabela Escravos Alforriados. Esta última, além dos dados já citados, apresenta os motivos, cláusulas, condições e justificativas das alforrias.

Trata-se de fontes fundamentais para o estudo da transmissão do patrimônio, pois os indivíduos nomeavam em seus testamentos o destino dos bens após a morte, apresentando seus herdeiros ascendentes ou descendentes e, na falta destes, as outras pessoas que não compunham o núcleo familiar.

Quando o testador casado ${ }^{7}$ falecia, o monte-mor, descontadas as dívidas e os custos com o inventário, ${ }^{8}$ era dividido em 6 partes. Três delas eram destinadas ao seu cônjuge, $2 / 3$ aos herdeiros e $1 / 3$, denominada terça, era disposto de acordo com a livre vontade do mesmo, podendo ser aplicada em alforrias, missas ou doações a irmandades, amigos e parentes. ${ }^{9}$ Quando o testador era solteiro, o monte-menor era dividido em três, sendo $2 / 3$ destinados aos her-

Anos 90, Porto Alegre, v. 14, n. 25, p.37-64, jul. 2007 
deiros e $1 / 3$, a terça, pertenceria aos legatários nomeados livremente pelo testador.

Face à riqueza de informações contidas nesses documentos, dentre o total de testamentos selecionamos um conjunto de 228 documentos compreendidos entre os anos 1840-1870 que foram deixados por mulheres, de modo a entender a constituição das suas fortunas pessoais e as formas de distribuição entre os herdeiros, deixando para uma etapa posterior o universo dos homens proprietários.

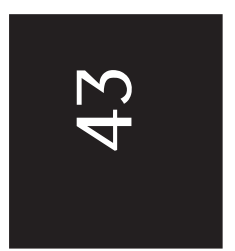

\section{Gráfico 2}

Testamentos selecionados como fonte documental para o estudo de transmissão de bens em São Paulo

$\square$

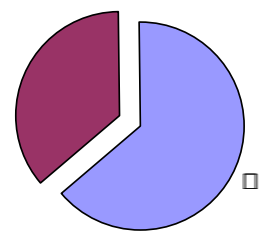

$\square$

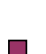

Fonte: Testamentos. $3^{\circ}$ Ofício da Família. São Paulo (Capital e Interior), 17631877. ATJSP/CEDHAL.

\section{As proprietárias e seus herdeiros}

Segundo consta nas Ordenações Filipinas, ${ }^{10}$ os herdeiros deveriam receber o mesmo valor de herança, independentemente de idade ou gênero. Essa quantia, denominada legítima, poderia ser deixada em objetos, móveis, escravos ou dinheiro.

No entanto, os testamentos nos permitem analisar o privilegiamento de determinado legatário (indivíduo que recebe a terça) na hora da partilha e as relações pessoais dos testadores. 
Senhoras e escravos na São Paulo do café (1840-1870)

Vejamos, a seguir, o testamento de Maria Antonia Guilhermina de Matos, de 01/12/1850. ${ }^{11}$ A testadora era casada e tinha 5 filhos, sendo 2 solteiros, 1 solteira, 1 casada e 1 viúva. A testadora dividiu a terça entre sua única filha casada, Jesuína Antônia, e sua única filha solteira, Querubina. Da metade destinada a Jesuína deveriam ser retiradas três doblas para os filhos da mesma, que, além de netos, eram afilhados da testadora.

Os legados também poderiam ultrapassar os limites do núcleo familiar, como verificamos no testamento de Gertrudes das Dores, registrado em 02/08/1853. ${ }^{12}$ A testadora não tinha herdeiros ascendentes nem descendentes, era solteira, e pôde dispor livremente sobre seu patrimônio. Assim, nomeou os seis escravos que havia alforriado na pia batismal, e mais outros cinco, que deixaria livres por sua morte, como seus herdeiros universais e legatários do remanescente de seus bens após cumpridas suas disposições. Aos sobrinhos, coube um sítio à beira da estrada, e às suas comadres, apenas o usufruto de casas, que após a morte pertenceriam aos herdeiros.

É interessante perceber, no caso acima, que os libertos da testadora foram privilegiados em detrimento dos sobrinhos, e que as comadres foram legatárias secundárias nessa partilha, fato incomum se comparado aos demais documentos, pois em geral, as mulheres solteiras no período analisado nomeavam irmãos e sobrinhos como herdeiros. Vejamos o caso de Escolástica Joaquina Ortiz, cujo documento foi elaborado em 17/08/1861. ${ }^{13}$ A testadora possuía 16 escravos e libertou 3 deles. Os demais cativos foram distribuídos entre os irmãos, sobrinhos e afilhados. Além disso, deixa talheres de prata a uma irmã e a terça parte de um imóvel que possui a um de seus irmãos. Quanto às disposições religiosas, a testadora declarou que era irmã de três Ordens religiosas e que deixaria $200 \$ 000$ para uma Igreja, além de pedir 5 capelas de missas por sua alma e pela alma de parentes.

Anos 90, Porto Alegre, v. 14, n. 25, p.37-64, jul. 2007 
Eni de Mesquita Samara et. al.

Outra forma de transmissão de bens verificada nos testamentos era o dote. Esse funcionava como um adiantamento da herança aos filhos ou filhas que pretendiam contrair matrimônio. Vale destacar que o filho dotado era privilegiado, pois recebia um legado antes dos demais herdeiros e poderia fazê-lo render. Além disso, teria descontado de sua legítima apenas metade do valor do dote. $^{14}$

Para exemplificar essa questão, podemos observar o testamento de Escolástica Jacinta Branca, elaborado em 16/05/1862.

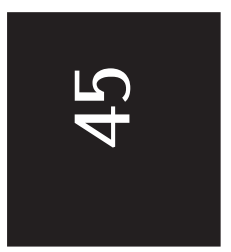
A testadora deixou todo o dote que havia recebido do segundo marido, Francisco Martins Bonilha, além de um oratório e um escravo, à sua filha do segundo casamento, Izabel Martins de Toledo. Uma das filhas recebeu roupas e as outras não tiveram bens legados além da legítima que lhes cabia. ${ }^{15}$

Como averiguamos através da análise dos testamentos, não era só às filhas que as testadoras legavam dotes. Eles podiam ser destinados, por exemplo, a mulheres pobres e órfãs. Por exemplo, Maria Innocencia de Souza Queiroz, em seu testamento de $22 / 01 / 1868$, deixou $2000 \$ 000$ de dote a duas órfãs pobres. ${ }^{16}$

O testamento poderia demonstrar, ainda, as preocupações religiosas do testador, através da solicitação de acompanhantes, missas e local de enterro. Além disso, o testador poderia citar as esmolas aos pobres, a encomendação da alma, as doações a Irmandades e Igrejas, de modo a garantir a sua salvação e até mesmo se distinguir socialmente.

É o caso de Gertrudes Abranges, que pediu em seu testamento para ser enterrada na Igreja de São Benedito, sem pompa, mas com decência. Solicitou ainda que fossem rezadas 50 missas por sua alma, 5 missas de corpo presente, 4 missas pela alma de seus pais e 8 por seu parente José Nogueira. Deixou em esmolas toda sua terça para ser repartida entre os pobres pedintes mais necessitados, segundo o juízo do seu testamenteiro, e mais $4 \$ 000$ a serem divididos igualmente entre 4 pobres. ${ }^{17}$ 
Outra testadora, Manoela Jardina da Silva, desejava ser enterrada na Igreja do Carmo, sem pompa, mas com decência. Encomendou sua alma a Deus. Deixou 200\$000 para as despesas do enterro e das missas. Doou ainda suas roupas de uso para serem repartidas entre suas escravas e entre os pobres, ao arbítrio de seu testamenteiro. ${ }^{18}$

Como se pode perceber pelos relatos das situações acima descritas, embora a legislação se preocupasse com a divisão igualitária entre os herdeiros independentemente do gênero, as testadoras em geral procuravam privilegiar alguns membros do núcleo familiar, ou mesmo fora dele. É perceptível também uma tendência entre as mulheres de destinar parte de seu legado para suas filhas, afilhadas, comadres e escravas, constituindo verdadeiras linhagens de sucessão feminina.

Percebemos ainda que as escravarias das mulheres proprietárias eram predominantemente femininas, e que essas cativas foram alforriadas em maior número nesse conjunto do que os homens.

Dada a importância desses indícios para a compreensão do processo de circulação de riqueza na cidade nesse momento, é que entendemos ser necessário verificar com mais cuidado o perfil das testadoras, o que faremos a seguir.

\section{Gráfico 3 - Gênero des escravos alforriados pelas testado- ras em São Paulo (1840-1870)}
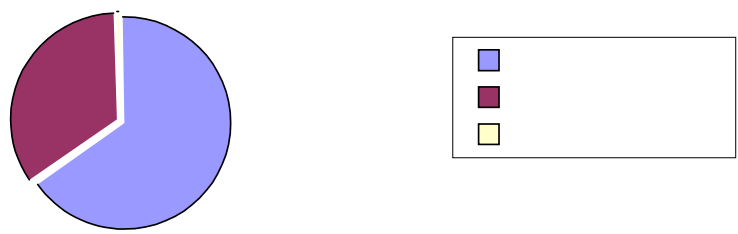

Fonte: Testamentos. $3^{\circ}$ Ofício da Família. São Paulo (Capital e Interior), 17631877. ATJSP/CEDHAL.

Anos 90, Porto Alegre, v. 14, n. 25, p.37-64, jul. 2007 



Senhoras e escravos na São Paulo do café (1840-1870)

Já 50\% das solteiras aparecem como proprietárias de imóveis. Caso não tivessem herdeiros necessários, fato provável, já que a maioria não tinha filhos e a menção a ascendentes é raríssima na documentação, era importante que especificassem seus bens e herdeiros para que fossem conhecidos após sua morte e cumpridas suas vontades.

Como exemplo de uma das formas de as mulheres terem adquirido seus imóveis, citamos o caso de uma testadora separada, Gertrudes Maria de Oliveira, cujo testamento de 03/12/1862 apresenta a seguinte declaração: "Sou senhora e possuidora de uma casa de um lance sita na rua da Esperança desta cidade sob número vinte e um a qual me foi doada por minha fallecida mãe por escriptura de data de dez de Novembro de mil oito cento e sincoenta e cinco $[. .]. "{ }^{19}$

Procuramos analisar, também, a posse de escravos das testadoras de acordo com o estado conjugal, e verificamos uma maior concentração de cativos entre as proprietárias solteiras, que possuíam, em média, 4,4 escravos. Esse índice era seguido pelas viúvas, que tinham, em média, 4,3 escravos; e divorciadas, com 3,3 cativos e com 2,9 escravos.

Quando observamos a média de escravos por cada mulher, considerando o total de testadoras, temos um índice de 4,1, dados que corroboram os números referentes à Província, os quais indicam pela pequena posse de escravos por proprietário, especialmente nas áreas urbanas. 


Eni de Mesquita Samara et. al.

Observamos a partir desses dados um grande índice de escravos alforriados através dos testamentos. Verificamos que $52 \%$ dos escravos foram libertos por suas proprietárias após a morte destas ou depois da prestação de serviços a algum herdeiro.

A maior incidência de alforrias foi concedida por mulheres divorciadas. Elas beneficiaram com esse privilegio $90 \%$ dos cativos que estavam em sua propriedade. Logo em seguida, encontramos, também, um elevado número de libertações promovidas pelas proprietárias casadas. Estas alforriaram 68\% dos seus escravos.

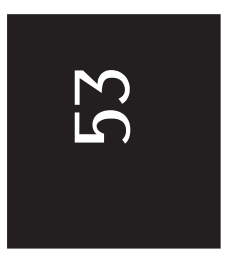

Entre as mulheres solteiras, esse benefício atingiu $60 \%$ da escravaria e, finalmente, as viúvas libertaram 37\% dos cativos. Importa-nos, ainda, ressaltar o significativo índice de alforrias promovidas por mulheres cujo estado conjugal não é informado na documentação. Elas alforriaram $68 \%$ de seu plantel.

Observamos uma maior incidência desse fenômeno entre as proprietárias que possuíam uma baixa média de filhos. Desse modo, cruzando as informações das tabelas 6 e 7 obtivemos os seguintes resultados: com uma média inferior a 1 filho, encontramos as mulheres solteiras e divorciadas, que libertaram respectivamente $90 \%$ e $60 \%$ de seus escravos. Com uma média de 1,6 filhos aparecem as mulheres casadas, que alforriaram $68 \%$ de seus escravos; e com uma quantidade maior de filhos, em média 3,3, encontramos as viúvas, que, confirmando essa tendência, libertaram um número menor de cativos, apenas $37 \%$.

Entre aquelas cujo estado conjugal não foi informado, ocorreu o mesmo fenômeno. Com uma média inferior a um filho, observamos um índice de libertações que atingiu 68\% de seus escravos.

Essa correspondência inversamente proporcional entre o número de alforrias e a média de filhos talvez possa ser atribuída ao fato de as mulheres que não possuíam (ou possuíam poucos) herdeiros necessários optarem por libertar a maior porção de seus escravos após sua morte. Por outro lado, as proprietárias com um maior número de herdeiros incluíam a maior parte dos seus cativos entre os bens a serem partilhados.

Anos 90, Porto Alegre, v. 14, n. 25, p.37-64, jul. 2007 
Senhoras e escravos na São Paulo do café (1840-1870)

Vejamos o caso de Maria Joaquina Cadaval, que teve o documento elaborado em 12/06/1852. ${ }^{21}$ A testadora era viúva, tinha 5 filhos e afirmou que nunca conseguiu fazer com que eles partilhassem os bens entre si, e nem mesmo ela pôde tomar posse de sua meação. Maria Joaquina possuía 23 escravos, aos quais não concedeu alforria. Seus escravos estavam distribuídos entre os filhos que viviam em sítios. A legatária, ou seja, aquela que recebeu a terça (que inclui escravos e casas) foi a única filha, Anna Joaquina da Luz, devido à companhia durante a enfermidade da testadora. Por fim, a testadora deixou um de seus escravos a seu neto e pediu 60 missas por sua alma, pela alma do marido e dos escravos falecidos em sua casa.

Esse exemplo corrobora com a referida assertiva que atesta uma menor incidência de alforrias entre as proprietárias com maior número de filhos. Elas optavam prioritariamente em doá-los para seus herdeiros.

Um exemplo que confirma uma propensão maior das mulheres com um baixo número de filhos em conceder alforrias aos cativos é o de Maria Ignacia da Conceição, cujo testamento foi elaborado em 15/03/1858. ${ }^{22}$ Ela era solteira, possuía 14 escravos e libertou todos. Possuía metade do valor de uma casa, que doou à sua prima, herdeira do remanescente dos bens. Possuía também a metade do valor de um sítio, que foi legado aos seus libertos. Além disso, a testadora era irmã da Ordem Terceira de Nossa Senhora do Carmo, e pediu 160 missas por sua alma e pela alma de seus pais e irmãos. 

Senhoras e escravos na São Paulo do café (1840-1870)

do matrimônio; um deles foi terem se referido aos filhos naturais como resultado de sua "fragilidade humana"; outro foi terem simplesmente informado os nomes, estados conjugais e, quando possível, nomes dos cônjuges dos filhos.

Assim, é interessante acompanhar alguns desses casos e as expressões usadas pelas testadoras na documentação para se referirem à questão dos filhos ilegítimos. Leonor do Carmo, que fez seu testamento em 08/09/1867, colocou-se da seguinte forma: "Declaro que sempre permaneci no estado de solteira, no qual, por minha fragilidade humana, tive os filhos que se seguem Doutor Olegario Herculano de Aquino e Castro, Domingos Henrique da Silva, Fortunata Olympia Xavier, e Candido Carlos de Mendonça Gitahy, os quaes por este meo testamento ficão reconhecidos, e como taes meos legitimos herdeiro". ${ }^{23}$ Leonor do Carmo foi uma das 11 testadoras solteiras que afirmaram ter tido filhos fora da constância do casamento, justificando esse fato por "fragilidade". Além dela, as três viúvas com filhos naturais reproduziram esse termo.

Já Jesuina Maria de São Pedro, em testamento de 29/08/ 1857, refere-se ao filho ilegítimo assim: "Declaro que no meo estado de solteira antes de casar-me com o dito Henrique Homero de Gois, tive hum filho de nome Jesuino Jose Soares, o qual se acha em minha companhia desde seo nascimento, e por isso o reconheço como meo legitimo filho, e unico herdeiro de todos os meos bens, que ficarem por meo fallescimento". ${ }^{24}$

Outro elemento interessante a ser observado no processo de alforria é a recorrência de doações de bens aos recém-libertos, como podemos observar através da Tabela 8 .

Anos 90, Porto Alegre, v. 14, n. 25, p.37-64, jul. 2007 

Senhoras e escravos na São Paulo do café (1840-1870)

Ao analisar a transmissão do patrimônio, fica claro, com relação a algumas das testadoras que doaram imóveis aos alforriados, que estas desejavam que os ex-cativos tivessem recursos para assegurar sua vida futura e vivessem de modo amigável sob o mesmo teto. Trata-se, portanto, de doações de caráter coletivo.

Por exemplo, o testamento de Anna Gertrudes de Góis, datado 25/03/1856, traz o seguinte texto: "Declaro que da porção de terras que possuo na circunvizinha desta Freguesia o meo testamenteiro dará o terreno de dez alqueires aos meos escravos que ficão libertos para igualmente irem trabalhando, e subsistirem com suas lavouras, não podendo elles disfazerem nem das casas, e nem do terreno que lhes deixo, pois que quero, que vivão amigos, e o restante das terras o meo testamenteiro mandará, a quem maior quantia offerecer e essa quantia será distribuída em igualdade pelos pobres desta minha Freguesia". ${ }^{25}$

Dessa mesma forma, no testamento já citado de Maria Ignacia da Conceição, elaborado em 15/03/1858, lemos a seguinte disposição: "Deixo pois essa metade do sitio que me pertence livre, e desembaraçada aos ditos meos escravos Anna, e aos seos filhos Antonio, Jose, Pedro, Catharina, Alexandrina, e a dita Marianna, e aos seos filhos Francisca, Maria Eugenia, Izabel, Amancio, Procedina, Catharina, e Guilhermina, para que no mesmo sitio viverem, e trabalhem para sua sub existência, com a condição porem de não poderem vender, e só o ultimo dos legatários mencionados, que sobre viver aos outros todos, he que poderá dispor d'essa metade do sitio, que lhes deixo, por sua morte". ${ }^{26}$

Entre os demais legados recebidos por alforriados, está a terça doada por uma testadora viúva e com 4 filhos a seu escravo, para que este pudesse inteirar o valor para a compra de sua liberdade; objetos, como roupas de uso, trastes ou corrente e cordão de ouro legados a 6 alforriados, sendo que 3 desses não receberam nada além dos objetos anteriormente citados. A 15 alforriados, coube o remanescente dos bens. 

Senhoras e escravos na São Paulo do café (1840-1870)

Com relação às alforrias de escravos, constatamos que a maioria das testadoras não se preocupou em explicar a razão da concessão. Assim, 232 libertações não apresentam alegações sobre o que poderia tê-las motivado. Em 24 dos casos o motivo citado para a manumissão foram os bons serviços prestados, em 3 a atenção, o zelo e também os bons serviços.

Outras justificativas, numericamente menos significativas, que apareceram na fonte documental foram a afeição, os bons serviços e a caridade no tratamento da testadora, a obediência, a companhia, a velhice, a concepção de filhos (mão-de-obra escrava) e o merecimento do cativo.

Como averiguamos, nesse período que antecede a abolição da escravatura há uma tendência muito forte entre as proprietárias de conceder alforrias aos cativos, pois $52 \%$ dos escravos declarados foram libertos.

Do total de alforriados, as escravas constituíram 64,7\%, enquanto os escravos, $35 \%$. Esse fato apontaria para um significativo privilégio das escravas; porém, ao verificarmos a divisão por gênero da população cativa declarada nos testamentos, percebemos que 312 eram mulheres, 190 homens, e de 13 não tivemos informações claras. Assim, concluímos que as porcentagens de manumissão foram altas para os escravos de ambos os gêneros, embora o índice no grupo de libertas, 56,4\%, tenha sido pouco maior do que no dos libertos, $47,9 \%$.

É interessante, também, observar que muitos desses cativos recebem bens, ou seja, $28 \%$ do total; as relações afetivas entre as senhoras e seus escravos também estão presentes nesses documentos, embora a maioria das testadoras não tivesse revelado os porquês dessa libertação. Mulheres solitárias e sem filhos eram proprietárias de escravarias médias, ou seja, entre 4 e 5 escravos por proprietária, e também concentravam parcela significativa dos bens imóveis. Notamos, ainda, que nesse grupo analisado algumas poucas mulheres estudadas faziam parte do topo da pirâmide

Anos 90, Porto Alegre, v. 14, n. 25, p.37-64, jul. 2007 
Eni de Mesquita Samara et. al.

social, possuindo escravarias de maior porte, entre 15 e 30 escravos e numerosos imóveis (sítios, morada de casas).

No entanto, as testadoras, em sua maioria, constituíam o que Araújo e Nazzari chamam de camadas médias nessa sociedade, possuindo pouca riqueza para distribuir entre os herdeiros.

Entretanto, mesmo os pequenos montantes apontam para a concentração da riqueza em mãos femininas que geriam famílias, negócios e propriedades, dispunham sobre a vida dos escravos e determinavam a divisão do legado.

Ladies of Coffee: gender, family and wealth in São Paulo (1840-1870).

Abstract. This article has as purpose to study women as owners of lands, goods and slaves, in the city of São Paulo, between 1840 and 1870, using as documentary source the wills of the 3rd Office Family, which belong to the ATJSP (Archives of the Court of Justice of São Paulo) and also to the collection of CEDHAL (Center of Studies of Historical Demography of Latin America). The aim is to analyze the process of wealth movement in the city, trying to understand mainly the constitution of women's fortunes and the transmission of wealth to the heirs. In this way, special attention will be paid to the women owners of slaves, as we try to understand the conditions in which the emancipations were given and the roles played by these slaves in the transmission of the heritage.

Keywords: Women. Heritage. São Paulo. Empire Brazil. Family. Gender.

\section{Notas}

${ }^{1}$ OLIVEIRA, Maria Luiza Ferreira de. Entre a casa e o armazém: relações sociais e experiência da urbanização, São Paulo, 1850-1900. São Paulo: Alameda, 2005.

${ }^{2}$ Maria Odila, Eni.

${ }^{3}$ ARAÚJO, Maria Lucília Viveiros. Os caminhos da riqueza dos paulistanos na primeira metade do oitocentos. São Paulo: Hucitec/FAPESP, 2006.

${ }^{4}$ NAZZARI, Muriel. O desaparecimento do dote: mulheres, famílias e mudança social em São Paulo, Brasil, 1600-1900. Trad. Lólio Lourenço de Oliveira. São Paulo: Companhia das Letras, 2001.

${ }^{5}$ Os codicilos, documentos redigidos para anular ou retificar os testamentos, dispondo, por exemplo, sobre alforrias e legados concedidos, complementaram as informações dos testamentos analisados.

Anos 90, Porto Alegre, v. 14, n. 25, p.37-64, jul. 2007 
Senhoras e escravos na São Paulo do café (1840-1870)

${ }^{6}$ Ainda nesse total, temos 12 codicilos de mulheres e 11 codicilos de homens. Mão comum é a denominação utilizada para designar testamentos feitos por duas pessoas ou mais.

${ }^{7}$ Para um estudo sobre o processo de transmissão de bens, poderíamos associar a análise dos testamentos aos inventários, pois são arrolamentos dos bens dos falecidos, que trazem informações minuciosas sobre as posses do indivíduo, como móveis, objetos, escravos, propriedades, utensílios, sua descrição e o valor de cada item. Além disso, neles constam os valores do patrimônio bruto (monte-mor), o valor do monte-mor líquido, especificações sobre dívidas e os nomes dos credores, a relação dos herdeiros, suas idades e estado civil e os valores das legítimas que deveriam receber.

${ }^{8}$ BACELLAR, Carlos de Almeida Prado. Família, herança e poder em São Paulo: 1765-1855. Estudos CEDHAL, n. 7. São Paulo: FFLCH/USP, 1991. A legítima era a quantia deixada a cada um dos herdeiros de forma eqüitativa, mas se o testador quisesse poderia privilegiar um dos herdeiros, dando a terça ou parte dela para o mesmo.

${ }^{9}$ A quantia que corresponderia à terça era somada aos $2 / 3$ destinados aos herdeiros e divida entre eles, caso o indivíduo falecesse sem deixar testamento.

${ }^{10}$ CEDHAL/ATJSP, $3^{\circ}$ Ofício da Família. São Paulo (Capital e Interior), 17631877. Testamento de Maria Antonia Guilhermina de Matos, 01/12/1850, doc. $\mathrm{n}^{\circ} 107$.

${ }^{11}$ CEDHAL/ATJSP, $3^{\circ}$ Ofício da Família. São Paulo (Capital e Interior), 17631877.

${ }^{12}$ Testamento de Gertrudes das Dores Barbosa, 02/08/1853, doc. n ${ }^{\circ} 132$. Nesse documento, a testadora afirma: "Deixo forros por minha morte a meos escravos Estevão, Florinda, Florencia, Gertrudes e Benedicta, e a elles instituo por meos universaes herdeiros, e lhes deixo o remanescente de meus bens, depois de cumprir as minhas disposiçoens. Ja forrei na pia baptismal e a que confirma esta alforria que doi a meos escravos Jezuina, Maria das Dores, Maria do Rozario, Felicia, Joaquina e Bernardina, os quaes serão igualmente herdeiros de meos bens com os acima nomeados". Assim, a testadora libertou 11 de seus 16 escravos. Os 5 que não foram alforriados ficaram "encostados" ao seu testamenteiro.

${ }^{13}$ CEDHAL/ATJSP, $3^{\circ}$ Ofício da Família. São Paulo (Capital e Interior), 17631877. Testamento de Escolástica Joaquina Ortiz, 17/08/1861, doc. no 358.

${ }^{14}$ Não seriam levados em conta, na partilha, os rendimentos obtidos a partir do capital inicial.

${ }^{15}$ CEDHAL/ATJSP, $3^{\circ}$ Ofício da Família. São Paulo (Capital e Interior), 17631878. Testamento de Escolástica Jacinta Branca, 16/05/1862, doc. no 378.

Anos 90, Porto Alegre, v. 14, n. 25, p.37-64, jul. 2007 
Eni de Mesquita Samara et. al.

${ }^{16}$ CEDHAL/ATJSP, $3^{\circ}$ Ofício da Família. São Paulo (Capital e Interior), 1763-1878. Testamento de Maria Innocencia de Souza Queiroz, 22/01/1868, doc. nº 487. A testadora deixou o remanescente da terça às suas netas.

${ }^{17}$ CEDHAL/ATJSP, $3^{\circ}$ Ofício da Família. São Paulo (Capital e Interior), 1763-1878. Testamento de Gertrudes Abranges, 02/09/1854, doc. no 147.

${ }^{18}$ CEDHAL/ATJSP, $3^{\circ}$ Ofício da Família. São Paulo (Capital e Interior), 17631877. Testamento de Manoela Jardina da Silva, 20/12/1854, doc. nº 163.

${ }^{19}$ CEDHAL/ATJSP, $3^{\circ}$ Ofício da Família. São Paulo (Capital e Interior), 1763-1878. Testamento de Gertrudes Maria de Oliveira, 03/12/1862, doc. nº 393, cx. 08.

${ }^{20}$ CEDHAL/ATJSP, $3^{\circ}$ Ofício da Família. São Paulo (Capital e Interior), 17631877. Testamento de Joaquina Antunes e Abreu, 29/10/18554, doc. no 155, cx. 03 ${ }^{21}$ CEDHAL/ATJSP, $3^{\circ}$ Ofício da Família. São Paulo (Capital e Interior), 17631877. Testamento de Maria Joaquina Cadaval, 12/06/18562, doc. no 122.

${ }^{22}$ CEDHAL/ATJSP, $3^{\circ}$ Ofício da Família. São Paulo (Capital e Interior), $1763-$ 1877. Testamento de Maria Ignacia da Conceição, 15/03/18558, doc. no 261. A testadora afirma: "Deixo pois essa metade do sitio que (q.) me pertence livre, e dembaraçada aos ditos (dos.) meos escravos Anna, e aos seos filhos Antonio, Jose, Pedro, Catharina, Alexandrina, e a dita (da.) Marianna, e aos seos filhos Francisca, Maria Eugenia, Izabel, Amancio, Procedina, Catharina, e Guilhermina, para (pa.) que (q.) no mesmo (mmo.) sitio viverem, e trabalhem para sua sub-existencia, com a condição porem de não poderem vender, e só o ultimo dos legatarios mencionados, que (q.) sobreviver aos outros todos, he que (q.) poderá dispor d'essa metade do sitio, que (q.) lhes deixo, por (pr.) sua morte.

${ }^{23}$ CEDHAL/ATJSP, $3^{\circ}$ Ofício da Família. São Paulo (Capital e Interior), 1763-1878. Testamento de Leonor do Carmo, 08/09/1867, doc. no 481, cx. 10.

${ }^{24}$ CEDHAL/ATJSP, $3^{\circ}$ Ofício da Família. São Paulo (Capital e Interior), 1763-1878. Testamento de Jesuina Maria de São Pedro, 29/08/1857, doc. no 248, cx. 05.

${ }^{25}$ CEDHAL/ATJSP, $3^{\circ}$ Ofício da Família. São Paulo (Capital e Interior), 1763-1877. Testamento de Anna Gertrudes de Góis, 25/03/1856, nº 206, cx. 04.

${ }^{26}$ CEDHAL/ATJSP, $3^{\circ}$ Ofício da Família. São Paulo (Capital e Interior), 1763-1877. Testamento de Maria Ignacia da Conceição, 15/03/1858, nº 261, cx. 05.

\section{Fontes manuscritas}

Testamentos e Inventários. $3^{\circ}$ Ofício da Família. São Paulo (Capital e Interior), 1763-1878. ATJSP/CEDHAL.

Anos 90, Porto Alegre, v. 14, n. 25, p.37-64, jul. 2007 
Senhoras e escravos na São Paulo do café (1840-1870)

\section{Fontes impressas}

Ordenações Filipinas Livro IV. (Edição fac-símile da edição feita por Candido Mendes de Almeida, Rio de Janeiro, 1870). Lisboa: Fundação Calouste Gulbenkian, 1985.

\section{Referências}

ARAÚJO, Maria Lucília Viveiros. Os caminhos da riqueza dos paulistanos na primeira metade do oitocentos. São Paulo: Hucitec/FAPESP, 2006.

BACELLAR, Carlos de Almeida Prado. Família, herança e poder em São Paulo: 1765-1855. Estudos CEDHAL, nº 7. São Paulo: FFLCH/USP, 1991.

BERTIN, Enidelce. Relações escravistas, relações de gênero e as cartas de liberdade. In: Alforrias em São Paulo do Século XIX: liberdade e dominação. São Paulo: Humanitas, 2004.

DIAS, Maria Odila Leite da Silva. Quotidiano e poder em São Paulo no século XIX. São Paulo: Brasiliense, 1995.

MARQUESE, Rafael Bivar de. A dinâmica da escravidão no Brasil: resistência, tráfico negreiro e alforrias, séculos XVII a XIX. Texto apresentado ao I Encontro entre Historiadores Colombianos e Brasileiros, promovido pelo Ibraco em Bogotá, Colômbia, agosto de 2005.

MATTOSO, Kátia M. Queirós. Testamentos de escravos libertos na Babia no século XIX. Uma fonte para o estudo das mentalidades. Salvador: Centro de Estudos Baianos, 1979 .

NAZZARI, Muriel. O desaparecimento do dote: mulheres, famílias e mudança social em São Paulo, Brasil, 1600-1900. Trad. Lólio Lourenço de Oliveira. São Paulo: Companhia das Letras, 2001.

Recebido em 31/05/2007

Autores convidados

Anos 90, Porto Alegre, v. 14, n. 25, p.37-64, jul. 2007 